\title{
Visual and Electrosensory Circuits of the Diencephalon in Mormyrids: An Evolutionary Perspective
}

\author{
MARIO F. WULLIMANN AND R. GLENN NORTHCUTT \\ Georg-August-Universität, Zentrum Anatomie, 3400 Göttingen, Federal Republic of Germany \\ (M.F.W.); University of California, San Diego, and Department of Neurosciences A-001, \\ Scripps Institution of Oceanography, La Jolla, California 92093 (R.G.N.)
}

\begin{abstract}
Mormyrids are one of two groups of teleost fishes known to have evolved electroreception, and the concomitant neuroanatomical changes have confounded the interpretation of many of their brain areas in a comparative context, e.g., the diencephalon, where different sensory systems are processed and relayed. Recently, cerebellar and retinal connections of the diencephalon in mormyrids were reported. The present study reports on the telencephalic and tectal connections, specifically in Gnathonemus petersii, as these data are critical for an accurate interpretation of diencephalic nuclei in teleosts. Injections of horseradish peroxidase into the telencephalon retrogradely labeled neurons ipsilaterally in various thalamic, preglomerular, and tuberal nuclei, the nucleus of the locus coeruleus (also contralaterally), the superior raphe, and portions of the nucleus lateralis valvulae. Telencephalic injections anterogradely labeled the dorsal preglomerular and the dorsal tegmental nuclei bilaterally.

Injections into the optic tectum retrogradely labeled neurons bilaterally in the central zone of area dorsalis telencephali and ipsilaterally in the torus longitudinalis, various thalamic, pretectal, and tegmental nuclei, some nuclei in the torus semicircularis, the nucleus of the locus coeruleus, the nucleus isthmi and the superior reticular formation, basal cells in the ipsilateral valvula cerebelli, and eurydendroid cells in the contralateral lobe $\mathrm{C} 4$ of the corpus cerebelli. Weaker contralateral projections were also observed to arise from the ventromedial thalamus and various pretectal and tegmental nuclei, and from the locus coeruleus and superior reticular formation. Tectal injections anterogradely labeled various pretectal nuclei bilaterally, as well as ipsilaterally the dorsal preglomerular and dorsal posterior thalamic nuclei, some nuclei in the torus semicircularis, the dorsal tegmental nucleus, nucleus isthmi, and, again bilaterally, the superior reticular formation.

A comparison of retinal, cerebellar, tectal, and telencephalic connections in Gnathonemus with those in nonelectrosensory teleosts reveals several points: (1) the visual area of the diencephalon is highly reduced in Gnathonemus, (2) the interconnections between the preglomerular area and telencephalon in Gnathonemus are unusually well developed compared to those in other teleosts, and (3) two of the three corpopetal diencephalic nuclei are homologues of the central and dorsal periventricular pretectum in other teleosts. The third is a subdivision of the preglomerular area, rather than an accessory optic or pretectal nucleus, and is related to electroreception. The preglomerulo-cerebellar connections in Gnathonemus are therefore interpreted as uniquely derived characters for mormyrids.
\end{abstract}

Key words: fish, Gnathonemus, tectal connections, telencephalic connections, vision

The South American gymnotoid fishes and the African mormyrids are the only two teleost groups (Fig. 1) known to have evolved an active electrosensory system that enables them to emit and perceive electric signals (Bullock et al., ' 82 , '83). Long before this was known, the complex nervous system of mormyrid fishes attracted the interest of comparative neuroanatomists (Erdl, 1846; Franz, '12, '13, '21;
Stendell, '14a,b,c; Berkelbach van der Sprenkel, '15; Suzuki, '32; Harder, '68; Nieuwenhuys and Nicholson, '69a; Wullimann and Senn, '81). The hypertrophy of the lateral line

Accepted April 5, 1990.

Address reprint requests to Dr. Mario F. Wullimann, Georg-AugustUniversität, Zentrum Anatomie, Kreuzbergring 36, 3400 Göttingen, FRG. 
Abbreviations

\begin{tabular}{ll} 
A & nucleus anterior thalami \\
CA & commissura anterior \\
C1 & corpus cerebelli, lobulus C1 \\
C2 & corpus cerebelli, lobulus C2 \\
C3 & corpus cerebelli, lobulus C3 \\
CP & nucleus centralis posterior thalami \\
CPN & nucleus pretectalis centralis \\
CPo & commissura posterior \\
CS & commissura suprachiasmatica \\
Dc & central zone of area dorsalis telencephali \\
Dd & dorsal zone of area dorsalis telencephali \\
Dl & lateral zone of area dorsalis telencephali \\
Dla & lateral part of Dl \\
Dlb & intermediate part of Dl \\
Dm & medial zone of area dorsalis telencephali \\
dot & dorsal optic tract \\
DP & nucleus dorsalis posterior thalami \\
DR & nucleus dorsalis tegmenti mesencephali pars rostralis \\
DT & nucleus tegmentalis dorsalis \\
EG & eminentia granularis \\
FLL & fasciculus longitudinalis lateralis \\
FLM & fasciculus longitudinalis medialis \\
FR & fasciculus retroflexus \\
g & nucleus gustatorius tertius \\
gr & granular layer of the valvula \\
H & habenula \\
Hy & hypophysis \\
l & lateral forebrain bundle \\
LC & nucleus of the locus coeruleus \\
LI & lobus inferior \\
LVd & nucleus lateralis valvulae pars dorsalis \\
LV1 & nucleus lateralis valvulae pars lateralis \\
LVv & nucleus lateralis valvulae pars ventralis \\
MD & nucleus mediodorgalis of the torus semicircularis \\
mo & molecular layer of the valvula \\
& \\
\hline
\end{tabular}

$\begin{array}{ll}\text { MV } & \text { nucleus medioventralis of the torus semicircularis } \\ \text { NDLI } & \text { nucleus diffusus of the inferior lobe } \\ \text { NE } & \text { nucleus exterolateralis of the torus semicircularis } \\ \text { NI } & \text { nucleus isthmi } \\ \text { NIn } & \text { nucleus interpeduncularis } \\ \text { NL } & \text { nucleus lateralis of the torus semicircularis } \\ \text { NPLI } & \text { nucleus periventricularis recessus lateralis of the inferior lobe } \\ \text { PD } & \text { nucleus lateralis valvulae pars perilemniscalis dorsalis } \\ \text { PGa } & \text { nucleus preglomerulosus anterior } \\ \text { PGc } & \text { nucleus preglomerulosus caudalis } \\ \text { PGd } & \text { nucleus preglomerulosus dorsalis } \\ \text { PGm } & \text { nucleus preglomerulosus medialis } \\ \text { PGr } & \text { nucleus preglomerulosus rostralis } \\ \text { PGv } & \text { nucleus preglomerulosus ventralis } \\ \text { PPd } & \text { nucleus pretectalis periventricularis pars dorsalis } \\ \text { PT } & \text { nucleus posterior thalami } \\ \text { PV } & \text { nucleus lateralis valvulae pars perilemniscalis ventralis } \\ \text { RT } & \text { nucleus tegmentalis rostralis of Grover and Sharma ('81) } \\ \text { SR } & \text { superior raphe nucleus } \\ \text { SRF } & \text { superior reticular formation } \\ \text { TA } & \text { nucleus tuberis anterior } \\ \text { Tel } & \text { telencephalon } \\ \text { TeO } & \text { tectum opticum } \\ \text { TL } & \text { torus longitudinalis } \\ \text { TMC } & \text { tractus mesencephalo-cerebellaris } \\ \text { TP } & \text { nucleus tuberis posterior } \\ \text { TPp } & \text { nucleus periventricularis of the posterior tuberculum } \\ \text { TS } & \text { torus semicircularis } \\ \text { TT } & \text { tractus toro-praeeminentialis } \\ \text { Va } & \text { valvula cerebeli } \\ \text { VL } & \text { nucleus ventrolateralis thalami } \\ \text { VM } & \text { nucleus ventromedialis thalami } \\ \text { vot } & \text { ventral optic tract } \\ \text { VP } & \text { nucleus ventroposterior of the torus semicircularis } \\ & \end{array}$

nerves and valvula cerebelli was not immediately recognized as such. Erdl (1846) interpreted the valvula as part of the telencephalon. Later, the classical controversy between Franz ('12, '13, '21) and Stendell ('14a,b,c) dealt with the question of whether the lateral line nerves and their higher order central nervous areas were not, in fact, facial nerves and their central nervous structures. Recently, electrophysiological, behavioral, and ecological studies (for recent reviews see Bell and Szabo, '86; Bell, '86; Hopkins, '86, '88) have extended our knowledge of mormyrid neurobiology, as have tracing studies with modern neuroanatomical methods (Maler et al., '73a,b; Bell and Russell, '78; Haugede-Carre,

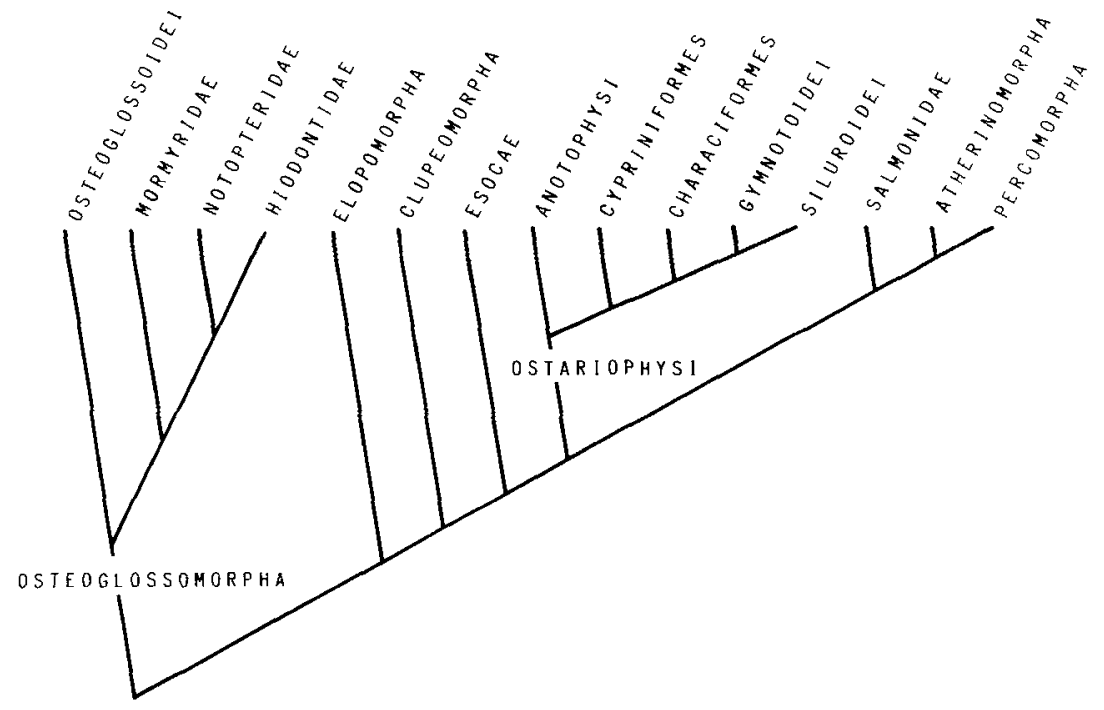

Fig. 1. Cladogram (after Lauder and Liem, '83) showing the systematical position of the osteoglossomorph mormyrids and the ostariophysine gymnotoids, the only known teleosts with an active electrosensory modality. 
TABLE 1. Comparison of Terminologies for Nuclei at Diencephalic Levels in Mormyrids

\begin{tabular}{|c|c|c|c|}
\hline $\begin{array}{l}\text { Wullimann and } \\
\text { Northcutt, } \\
\text { present study }\end{array}$ & $\begin{array}{l}\text { Meek et al., } \\
\text { '86a }\end{array}$ & $\begin{array}{l}\text { Lazar et al., } \\
\text { ' } 84\end{array}$ & $\begin{array}{l}\text { Stendell, } \\
\text { '14 }\end{array}$ \\
\hline dorsal periventricular pretectal nucleus, PPd & nucleus commissurne posterioris, NPC & $\begin{array}{l}\text { optic nucleus of the posterior commissure, } \\
\text { ONPC }\end{array}$ & 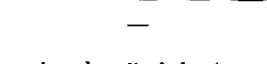 \\
\hline $\begin{array}{l}\text { central pretectal nucleus, } \mathrm{CPN} \\
\text { rostral preglomerular nucleus, } \mathrm{PG} \text { r }\end{array}$ & $\begin{array}{l}\text { nucleus geniculatus, } \mathrm{NG} \\
\text { nucleus rotundus, } \mathrm{NR}\end{array}$ & $\begin{array}{l}\text { pretectal nucleus, } P N \\
\text { nucleus rotundus, } N R \text { + lateral geniculate } \\
\text { nucleus, } L G N\end{array}$ & $\begin{array}{l}\text { nucleus dorsalis thalami } \\
\text { nucleus anterior thalami }\end{array}$ \\
\hline $\begin{array}{l}\text { dorsal preglomerular nucleus, } P G d \\
\text { ventral preglomerular nucleus, } P G v \\
\text { caudal preglomesular nucleus, } \mathbf{P G e}\end{array}$ & $\begin{array}{l}\text { nucleus donsalis anterior pretectalis, DAP } \\
\text { thalamus TH } \\
\text { nucleus postventralis thalami, NPV }\end{array}$ & $\begin{array}{l}\text { thalamus, TH } \\
\text { thalamus, TH }\end{array}$ & $\begin{array}{l}\text { nucleus ventralis thalami } \\
\text { nucleus ventralis thalami }\end{array}$ \\
\hline
\end{tabular}

'79, '83; Bell, '81a,b; Bell et al., '81; Finger et al., '81; Szabo, '83; Meek et al., ' $86 a, b)$. These studies have focused primarily on the neurobiology of electroreception, as the hypertrophy of the related neural structures facilitates the analysis of this sensory system.

In contrast, very little experimental information is available for other sensory systems in mormyrids. However, studies of retinal efferents (Lazar et al., '84; Meek et al., ' $86 \mathrm{~b}$ ) indicate that primary visual projections are less extensive than in most other teleosts (Northcutt and Wullimann, '88). This suggests that as electroreception developed in mormyrid evolution, there may have been a concomitant reduction in vision.

In all vertebrates, information from different sensory systems, such as vision, hearing, gustation, and lateral line mechanoreception, is processed and relayed in the diencephalon. Whereas electroreception evolved anew in mormyrids (Bullock et al., '82, '83), vision was reduced in this group of fishes (Lazar et al., '84). This may be reflected in major differences in the organization of the diencephalon in mormyrids. However, a description of the diencephalon in this group has never been undertaken in a comparative context, and a unique neuronatamical nomenclature has developed for most of its areas.

We recently discussed the evolution of the visual system in teleost fishes by placing existing connectional information in the context of a phyletic analysis (Northcutt and Wullimann, '88). This analysis, as well as information on cerebellar connections in percomorph and cyprinid teleosts (Wullimann and Northcutt, '88) and mormyrids (Meek et al., ' $86 \mathrm{a}, \mathrm{b})$, now provides a basis for examining the morphology of the diencephalon in mormyrids. Specifically, in nonelectroreceptive teleosts there are four corpopetal nuclei at diencephalic levels, and all four are retinofugal; in mormyrids there are only three diencephalic nuclei that are corpopetal, and only two of these are retinofugal. Such discrepancies in diencephalic organization can be explained only if one takes all connectional information into account. This study therefore reports on the tectal and telencephalic connections in Gnathonemus petersii, as information on these connections is critical for an accurate interpretation of diencephalic nuclei in mormyrids.

The results have necessitated some new terms that are justified in the discussion. The nomenclature used is compared with that of previous studies in Table 1 . In general, we use the nomenclature of Weston ('37), as modified by Nieuwenhuys ('63), for the telencephalon, of Braford and Northcutt ('83), as modified by Northcutt and Wullimann ('88), for the diencephalon, and of Meek et al. ('86a,b) for the remainder of the brain.

A preliminary report of this work has appeared previously (Wullimann and Northcutt, '87).

\section{MATERIAL AND METHODS Animals}

Elephant-nose fish, Gnathonemus petersii (standard length: $5-15 \mathrm{~cm}$ ), were obtained from local dealers. The animals were kept in filtered communal tanks at $27^{\circ} \mathrm{C}$, and fed daily.

\section{Experimental procedures}

The animals were anesthetized presurgically in a dilute solution of MS 222 (tricaine methanesulfonate, Sigma). For injections into the telencephalon, the brain was exposed in one of two ways: (1) a skin flap was cut unilaterally, dorsal to the telencephalon; a small hole was drilled in the cranium; and the underlying valvula cerebelli was pushed medially to expose the dorsal telencephalon; (2) one eye was removed, and a small piece of bone was detached from the orbit with fine forceps to expose the lateral telencephalon. The latter approach was also used for injections into the optic tectum.

An insect pin (size 000) was coated with either horseradish peroxidase (HRP, Sigma VI) or horseradish peroxidase conjugated to wheat germ agglutinin (WGA-HRP, Sigma) in order for us to inject the appropriate brain area. The HRP was injected in seven animals (one retinal, three tectal, and three telencephalic cases); WGA-HRP was injected in nine animals (five tectal and four telencephalic cases). Gelfoam (Upjohn) saturated with teleost Ringer's solution was placed on the injection site and the wound was closed with histoacryl (Braun Melsungen, FRG). In cases where the brain was approached through the orbit, the skin surrounding the empty eye socket was sutured to stabilize the gelfoamhistoacryl wound closure. Tetracycline $(1 \mathrm{mg} / 100 \mathrm{~g}$ body weight) was injected intraperitoneally before the animals were revived.

Postsurgical animals were isolated in plastic containers within the home tank, and the water was treated with Ampicillin (Sigma; $1 \mathrm{mg} / 1$ gallon). Survival times were 6 days (retinal case) or 2-7 days (telencephalic cases and tectal cases), after which the animals were reanesthetized with MS 222 and perfused transcardially with $1 \%$ Heparin (Elkins-Sinn, Inc.) in teleost Ringer's solution, followed by $4 \%$ glutaraldehyde in $0.1 \mathrm{M}$ phosphate buffer ( $\mathrm{pH} 7.4$ ). The brains were removed, postfixed for 2-3 hours in the same fixative plus $30 \%$ sucrose, embedded in a gelatin $(10 \%)$ sucrose $(30 \%)$ medium, and again postfixed for 4 hours in fixative-sucrose before being transversely frozen sectioned at $35 \mu \mathrm{m}$. The sections were reacted according to the Hanker-Yates protocol (Hanker et al., '77) or the heavy metal intensified diaminobenzidine protocol (Adams, '81) before being mounted on chrom-alum-coated slides and counterstained with a $1 \%$ methyl-green solution. 


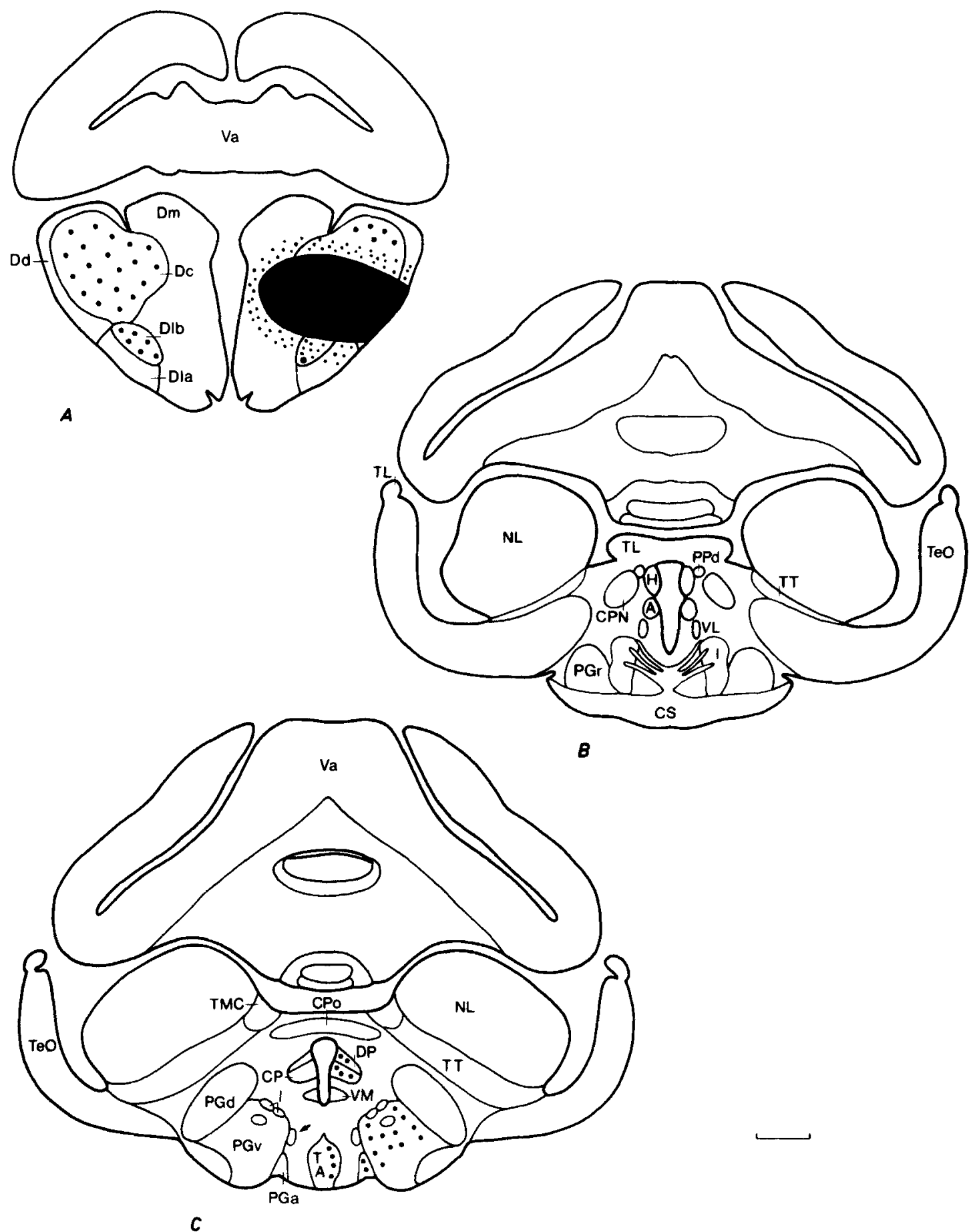

Fig. 2, Camera lucida drawings of cross sections through the brain of Gnathonemus showing results of an HRP injection into the telencephalon. Solid black and adjacent dots: injection site and surrounding area; large dots: retrogradely labeled neurons; small dots: anterogradely labeled nuclei; arrow: medial fascicle of the lateral forebrain bundle. Bar scales $=0.5 \mathrm{~mm}$. 


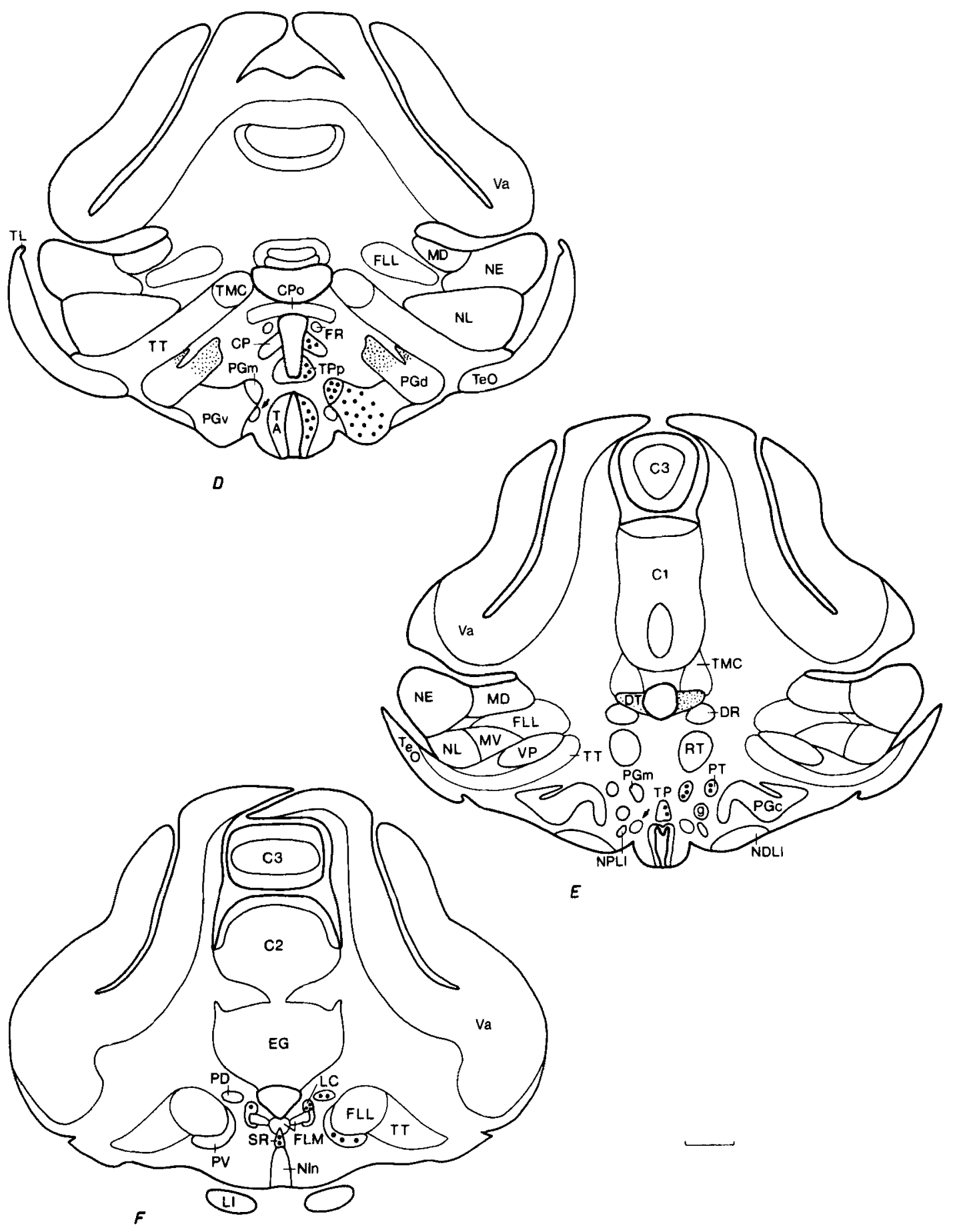

Figure 2 (continued)

\section{Normal anatomy}

For a reference series of brain sections, one specimen of Gnathonemus petersii was anesthetized with MS 222 and perfused with $1 \%$ Heparin in teleost Ringer's solution, followed by AFA $(90 \mathrm{ml} 80 \%$ ethanol, $5 \mathrm{ml}$ formalin, $5 \mathrm{ml}$ glacial acetic acid). The brain was removed from the skull and postfixed for 2 months in AFA before being embedded in paraffin and cut transversely at $15 \mu \mathrm{m}$. The sections were mounted on slides, reacted with Bodian silver, and counterstained with cresyl violet.

\section{RESULTS}

The telencephalic (Fig. 2) connections are reported first, followed by a description of the tectal (Fig. 3) and retinal connections in Gnathonemus. 


\section{Telencephalic connections}

The massive lateral forebrain bundle was heavily labeled from the telencephalon to the diencephalon by unilateral injections into the area dorsalis telencephali, mainly in the dorsal (Dd), central (Dc), and medial (Dm) divisions, but also in the dorsalmost portions of the intermediate (Dlb) and lateral (Dla) parts of the lateral (Dl) division. Within the diencephalon the lateral forebrain bundle splits into smaller fascicles and enters the preglomerular area and hypothalamus. A medial fascicle (arrow in Fig. 2C-E) labeled by our injections continues caudally and then dorsally to terminate in the dorsal tegmental nucleus.

Afferent telencephalic connections. Unilateral injections into the telencephalon retrogradely labeled neurons in the contralateral telencephalon in Dc and Dlb (Fig. 2A). At diencephalic levels, retrogradely filled nuclei included the ipsilateral dorsal posterior and central posterior thalamic nuclei, the anterior, medial, and ventral preglomerular nuclei, and the anterior and posterior tuberal nuclei, as well as the periventricular nucleus of the posterior tuberculum, and the posterior thalamic nucleus (Figs. 2B,C,D,E, 4A). At more caudal, isthmic levels, four additional nuclei were found to project ipsilaterally to the telencephalon: the nucleus of the locus coeruleus (which was also labeled contralaterally), the superior raphe nucleus, and dorsal and ventral divisions of the scattered perilemniscal part of nucleus lateralis valvulae (Figs. 2F, 4D) (nucleus lateralis valvulae, pars perilemniscalis of Meek et al., ' $86 a, b$ ).

Efferent telencephalic connections. The same injections into the telencephalon revealed a bilateral, almost equally heavy terminal field in the dorsal preglomerular nucleus (Figs. 2D, 4B) and a predominantly ipsilateral field, with very weak contralateral labeling, in the dorsal tegmental nucleus (Figs. 2E, 4C). Sparse fibers could be seen to reach the lateral nucleus of the torus semicircularis (Fig. 4B) and the inferior lobes ipsilaterally, but no distinct terminal fields were observed.

\section{Tectal connections}

Afferent tectal connections. Injections into the rostral optic tectum revealed retrogradely filled neurons bilaterally in the telencephalon within Dc (Fig. 3A). At diencephalic levels, the retrogradely labeled cell groups included the ipsilateral torus longitudinalis, the ventromedial, ventrolateral, and dorsal posterior thalamic nuclei, and the dorsal periventricular and central pretectal nuclei (Fig. 3B,C). The dorsal periventricular and central pretectal nuclei were strongly labeled contralaterally, and the contralateral ventromedial thalamic nucleus was weakly labeled (Fig. 5A). Within the mesencephalon, the rostrodorsal tegmental nucleus (nucleus dorsalis tegmenti mesencephali pars rostralis of Meek et al., '86a,b) and the rostral tegmental nucleus of Grover and Sharma ('81) were labeled ipsilaterally and, more weakly, contralaterally (Figs. 3E, 5C). Furthermore, all subdivisions of the ipsilateral torus semicircularis, except nucleus exterolateralis, were retrogradely labeled: mediodorsal, medioventral, ventroposterior, and lateral nucleus of the torus semicircularis (Figs. 3C,D,E,F, 5B). At isthmic levels, the nucleus of the locus coeruleus, the superior reticular formation, and the nucleus isthmi were ipsilaterally labeled; the locus coeruleus and superior reticular formation showed weaker label contralaterally (Figs. 3G,H, 5D).

Within the valvula cerebelli, large cells at the border of the granular layer were seen consistently at the bottom of the valvular ridges and were labeled only ipsilaterally (Figs. $3 \mathrm{E}, 6 \mathrm{~B})$. These retrogradely labeled cells are in the exact position where basal cells have been reported in the valvula in mormyrids (Nieuwenhuys and Nicholson, '69b). In contrast, similar cells (eurydendroid cells of Nieuwenhuys et al., '74) in the corpus cerebelli (lobe C4, not charted in Fig. 3) were labeled only contralaterally.

Efferent tectal connections. Injections into the optic tectum revealed terminal fields at diencephalic levels ipsilaterally in the dorsal periventricular and central pretectal nuclei, the dorsal preglomerular nucleus, and the dorsal posterior thalamic nucleus (Fig. 3B,C,D). The central and dorsal periventricular pretectal nucleus also revealed terminals contralaterally. Three nuclei of the torus semicircularis receive ipsilateral input from the optic tectum: the medioventral, ventroposterior, and lateral nuclei. The mediodorsal nucleus (Fig. 3D,E,F) does not receive such input. Neurons of another mesencephalic nucleus, the dorsal tegmental nucleus, receive peculiar giant terminals labeled ipsilaterally (Figs. 3E, 6A). These giant axonal endings measure approximately $4 \mu \mathrm{m}$ in diameter. More caudally, the ipsilateral nucleus isthmi and the superior reticular formation were anterogradely labeled (Figs. $3 \mathrm{G}, \mathrm{H}, 5 \mathrm{D}$ ), the latter more weakly also on the contralateral side.

\section{Retinal connections}

The course and termination of retinofugal fibers were recently reported in Gnathonemus (Lazar et al., '84) and are not reported in detail here. Our retinal injection was made primarily to provide original experimental material for comparison with the telencephalic and tectal cases. We largely agree on the pattern of terminal areas reported by Lazar et al. ('84) and confirmed by Meek et al. ('86b). For the purpose of the present study, it is important to note that we also observed fibers terminating in the dorsal periventricular pretectal nucleus (optic nucleus of the posterior commissure of Lazar et al., '84) and in the central pretectal nucleus (pretectal nucleus of Lazar et al,, '84). However, we did not observe a terminal field in the position where the parvicellular superficial pretectum would be expected (lateral geniculate nucleus of Lazar et al., '84).

\section{DISCUSSION}

The retinal, tectal, and telencephalic connections of the diencephalon in Gnathonemus are discussed first, with emphasis on the corpopetal nuclei reported by Meek et al. ('86a,b), followed by consideration of tectal and telencephalic connections outside the diencephalon.

\section{A new interpretation of the diencephalon in mormyrids}

Retinal connections. The available experimental data on retinal projections in Gnathonemus (Lazar et al., '84; Meek et al., ' $86 \mathrm{~b}$; this study) indicate that many wellestablished retino-recipient areas in teleosts (for a recent review see Northcutt and Wullimann, '88) are extremely reduced or absent in mormyrids. Although the dorsal and ventral thalamus, the suprachiasmatic nucleus, the dorsal periventricular pretectal nucleus (nucleus commissurae posterioris of Meek et al., '86a,b), and the optic tectum appear to have visual afferents comparable to those in other teleosts (Lazar et al., '84), other primary visual regions receive limited or no visual input. We confirm that the central pretectal nucleus (pretectal nucleus of Lazar et al., '84; 


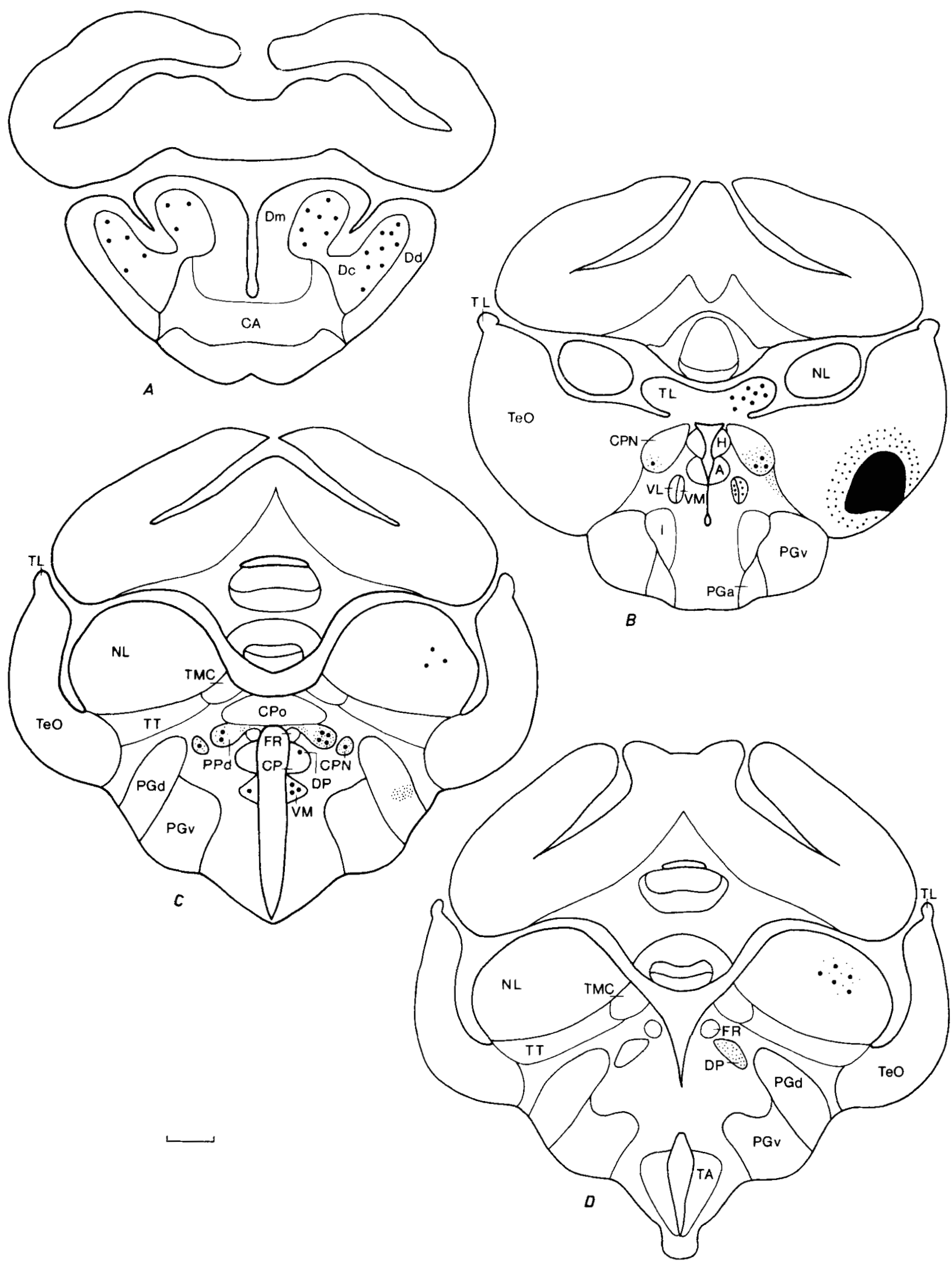

Fig. 3. Camera lucida drawings of cross sections through the brain of Gnathonemus showing results of an HRP injection into the optic tectum. Solid black and adjacent dots: injection site and surrounding area; large dots: retrogradely labeled neurons; small dots: anterogradely labeled nuclei. Bar scales $=0.5 \mathrm{~mm}$. 

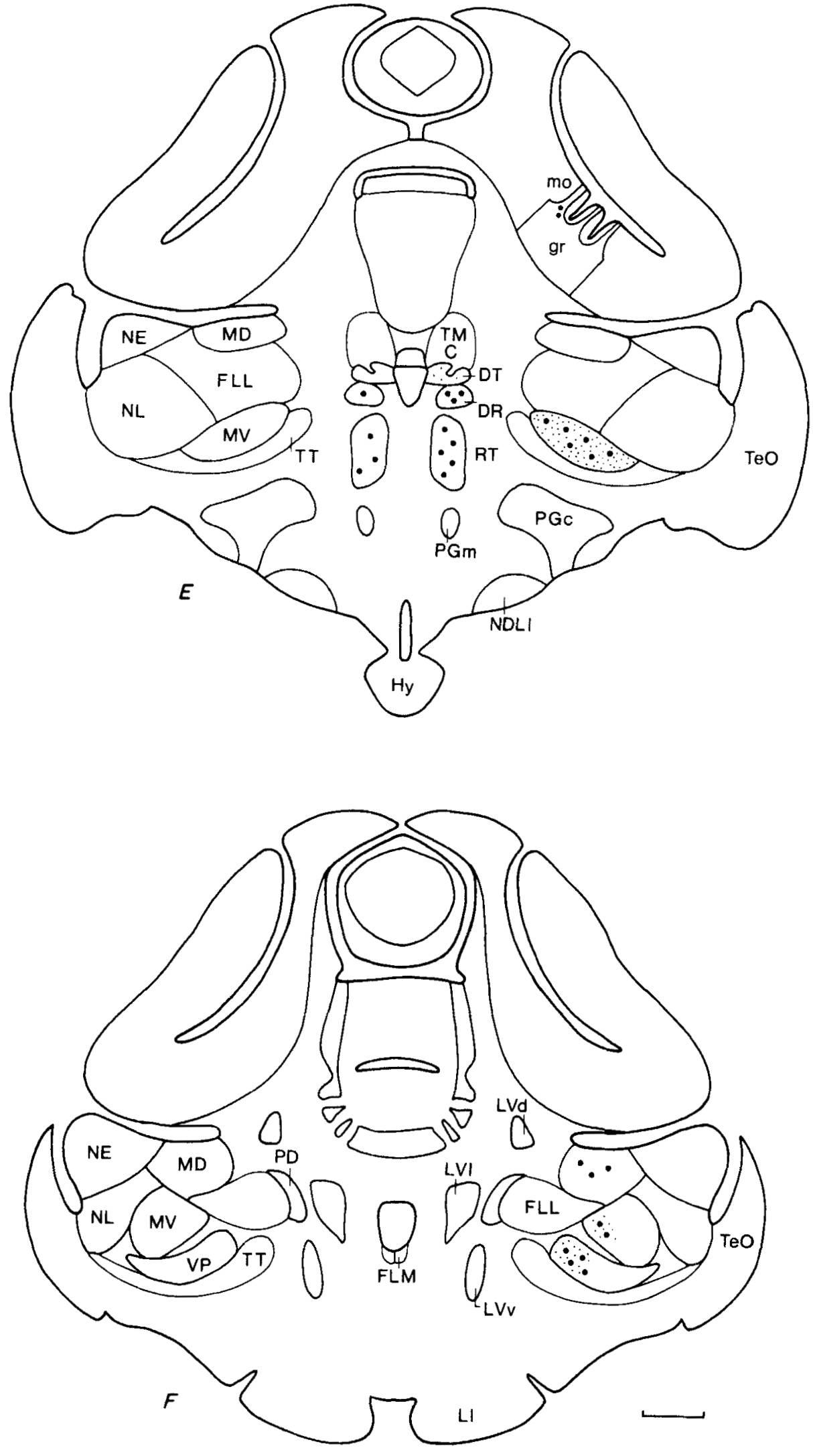

Figure 3 (continued) 

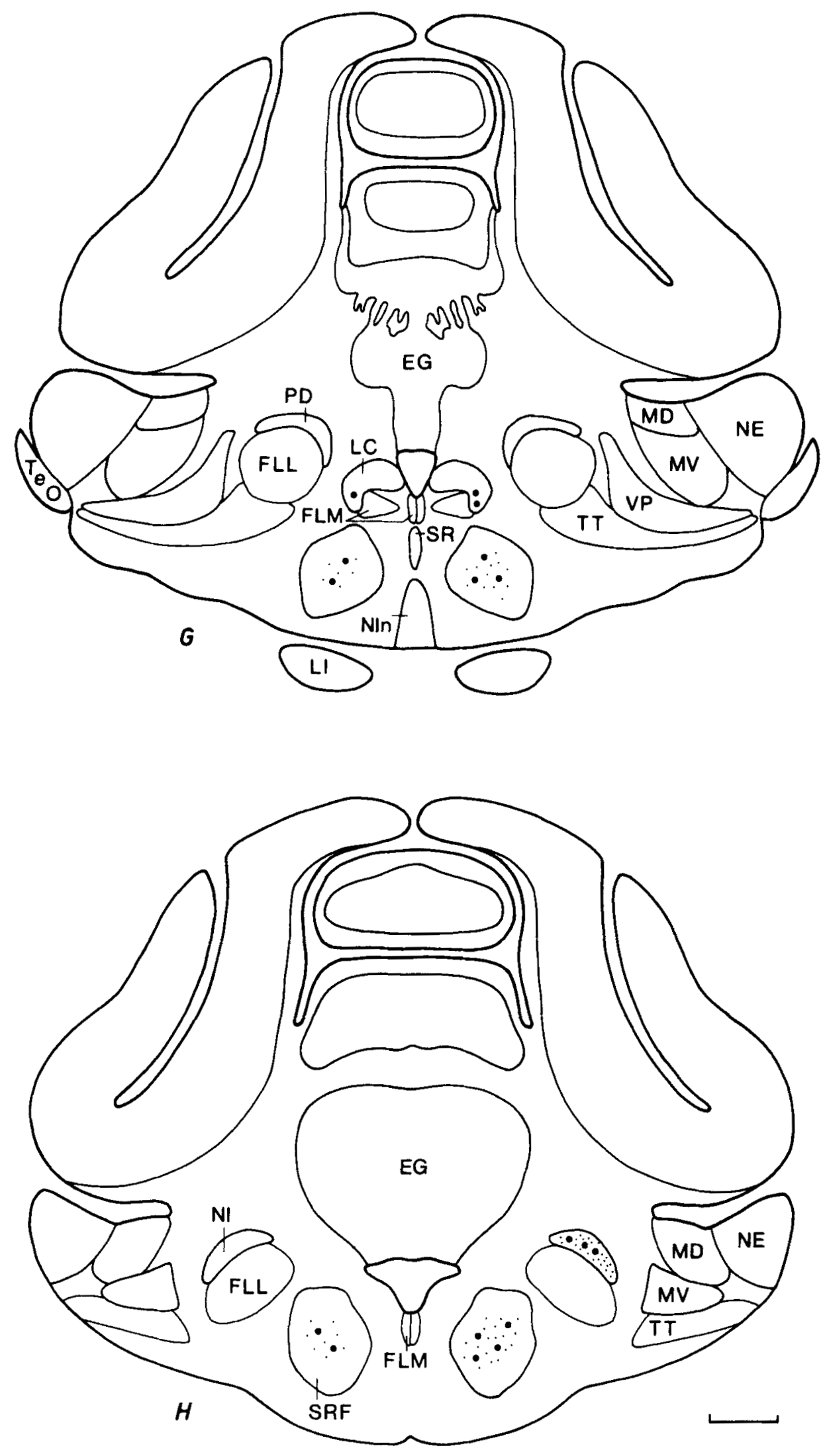

Figure 3 (continued) 

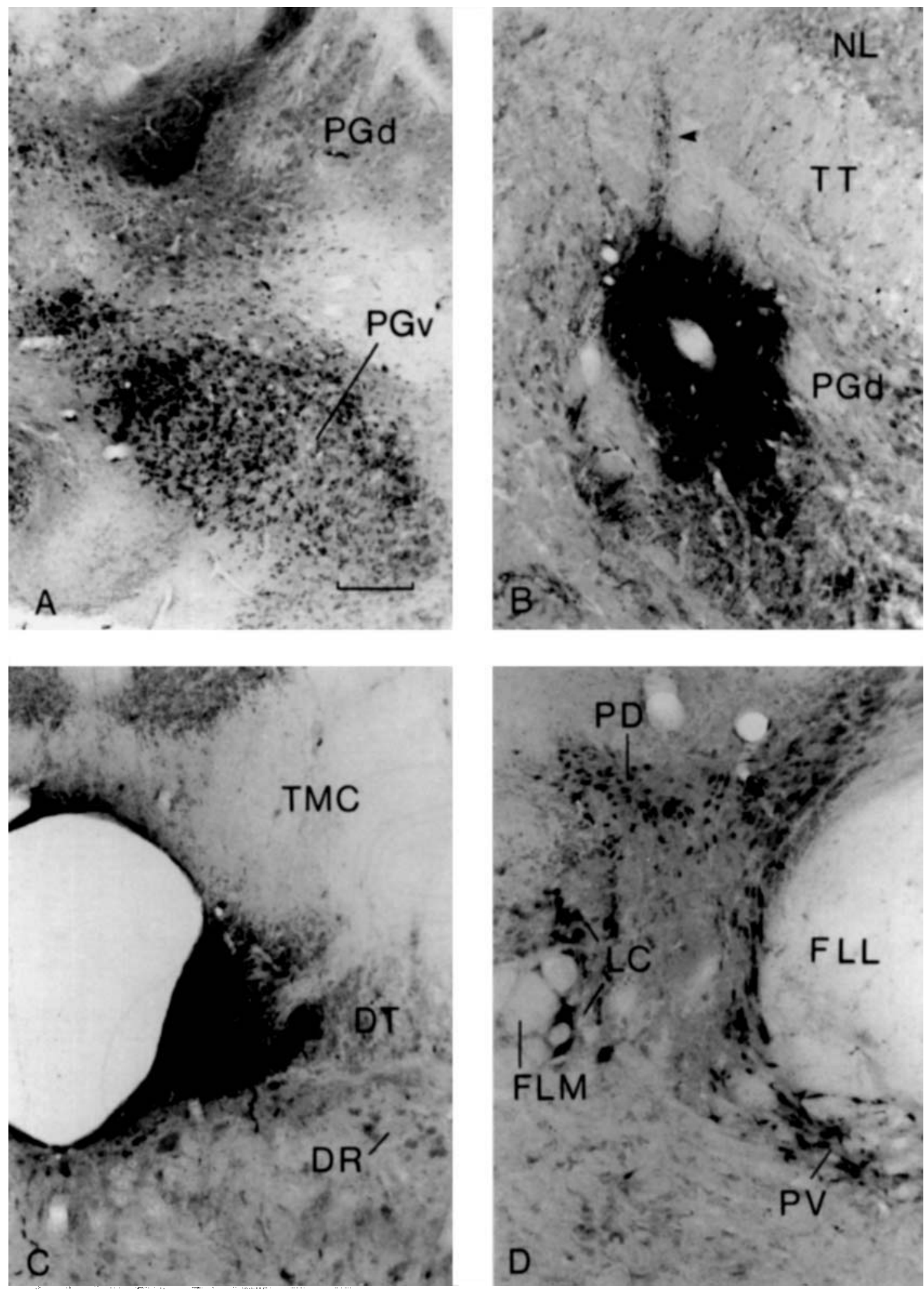

Fig. 4. Photomicrographs of cross sections through the brain of Gnathonemus showing nuclei labeled by injections of WGA-HRP (A) or HRP (B-D) into the telencephalon. Medial is to the left, dorsal to the top in all frames. Bar scale $=0.1 \mathrm{~mm}$ for all frames. A. Heavy retrograde label in the ventral and anterograde label in the dorsal preglomerular nucleus. B. Terminal field originating in the telencephalon in the dorsal

preglomerular nucleus at its greatest extent. Note some fibers (arrowhead) that pass the toro-preeminential tract and will reach the lateral nucleus of the torus semicircularis. C. Terminal field originating in the telencephalon in the dorsal tegmental nucleus. Ventrally, note the unlabeled rostrodorsal tegmental nucleus and its larger neurons. D. Retrogradely labeled nuclei in the isthmic region. 
nucleus geniculatus of Meek et al., '86a,b) receives retinal input only in its lateral part. However, no central nervous areas comparable to the retinorecipient parvicellular superficial pretectal nucleus or the dorsal and ventral accessory optic nucleus of other teleosts (Northcutt and Wullimann, '88) can be recognized in our Gnathonemus material, either in normal anatomy or in retinal preparations. In contrast, Lazar et al. ('84) recognized a minute retinal projection to a 'lateral geniculate nucleus' and to an area named 'terminal field of the accessory optic fibers'.

Tectal connections. Our tectal cases demonstrate that the dorsal periventricular and central pretectal nuclei (nucleus commissurae posterioris and nucleus geniculatus of Meek et al., ' $86 \mathrm{a}, \mathrm{b})$ in Gnathonemus have bilateral reciprocal connections with the optic tectum. The ventromedial and ventrolateral parts of the thalamus project ipsilaterally and, more weakly, contralaterally to the optic tectum, and the dorsal posterior thalamus has an ipsilateral reciprocal connection with the tectum. Similar tectal connections have been reported in other ray-finned fishes (Northcutt and Butler, '80; Luiten, '81; Northcutt, '82). Surprisingly, no terminal field was seen in the area rostral to the dorsal and ventral preglomerular nuclei in Gnathonemus, an area where the superficial pretectum (nucleus rotundus of Meek et al., '86a,b, nucleus rotundus and lateral geniculate nucleus of Lazar et al., '84) would be expected. In other teleosts, the superficial pretectum is subdivided into at least two parts: a retinofugal parvicellular part and a tectofugal magnocellular part (Northcutt and Wullimann, '88), which are histologically very different. In contrast, Gnathonemus has a relatively undifferentiated cell group in this position. Although other authors have reported that a small portion of this nucleus is retinofugal (lateral geniculate nucleus of Lazar et al., '84), we could not confirm this result. Furthermore, tectal efferents, which are diagnostic for the magnocellular part of the superficial pretectum in teleosts (Northcutt and Wullimann, '88), were not present in this cell group. However, horseradish peroxidase injections into the lateral and intermediate parts of the lateral zone of the area dorsalis telencephali result in heavy labeling of this rostral area, both anterogradely and retrogradely (D.J. Rooney, personal communication). Reciprocal connections between the preglomerular area and the telencephalon have been seen in all teleosts examined, but never reciprocal connections between the superficial pretectum and the telencephalon (Northcutt and Wullimann, '88). Therefore we interpret this "pretectal" area in Gnathonemus as the most rostral division of the preglomerular area (PGr in Fig. 2B).

We report a restricted tectal terminal field (Fig. 3C) within the lateral part of the dorsal preglomerular nucleus (nucleus dorsalis anterior pretectalis of Meek et al., '86a,b), corroborating previous reports that the preglomerular area of some teleosts is tectofugal (Ebbesson and Vanegas, '76; Luiten, '81).

Telencephalic connections. As in other ray-finned fishes (Ito and Kishida, '78; Ebbesson, '80; Ito et al., '80; Echteler and Saidel, '81; Northcutt, '81; Murakami et al., '83, '86a; Ito and Vanegas, '84), the preglomerular area (ventral, medial, and anterior preglomerular nucleus and posterior thalamic nucleus) and the dorsal and central posterior thalamus, and the posterior tuberculum (nucleus tuberis posterior; periventricular nucleus of the posterior tuberculum) in Gnathonemus project massively to the telencephalon. However, none of the three corpopetal nuclei in the diencephalon projects to the telencephalon, although one (the dorsal preglomerular nucleus) receives heavy telencephalic input. In many other teleosts, a major preglomerular nucleus, the lateral preglomerular nucleus, is reciprocally connected to the telencephalon. In Gnathonemus a similarly positioned, ventral preglomerular nucleus projects to the telencephalon, and a dorsal preglomerular nucleus receives a projection from the telencephalon. In terms of their relationship with the telencephalon, these two nuclei in Gnathonemus thus resemble a single nucleus, the lateral preglomerular nucleus, in other teleosts. However, dorsal and ventral, as well as rostral and caudal, preglomerular nuclei in Gnathonemus cannot be homologized with preglom erular divisions described in other teleosts, such as Carassius (Braford and Northcutt, ' 83 ), as, at present, it is impossible to determine the plesiomorphic condition for the preglomerular area in teleosts.

Furthermore, different parts of the torus semicircularis project to the dorsal and ventral preglomerular nucleus (Bell, '81b; Finger et al., '81): the dorsal preglomerular nucleus receives a projection from the lateral (ampullary organ/mormyromast related) nucleus of the torus semicircularis; the ventral preglomerular nucleus receives input from the mediodorsal (octavolateralis related) nucleus of the torus semicircularis. In nonelectrosensory teleosts, the (mechanosensory) lateral torus semicircularis projects to the lateral preglomerular nucleus (Echteler, '84; Murakami et al., ' $86 \mathrm{~b}$ ). This ascending mechanosensory pathway leading from the torus semicircularis to the preglomerular complex has also been reported recently in nonteleost ray-finned fishes (McCormick, '89), suggesting that it is ancestral for these fishes.

Conclusions. Data on the retinal, tectal, and telencephalic connections of the diencephalon in mormyrids allow four major conclusions:

1. Visual areas of the diencephalon are considerably reduced in mormyrids, particularly the superficial pretectum and the accessory optic nuclei.

2. Similarities in retinal, tectal, and cerebellar connections allow us to recognize nucleus commissurae posterioris and nucleus geniculatus of Meek et al. ('86a,b) as the homologues of the dorsal periventricular and central pretectal nucleus, respectively, in other teleosts (as reviewed by Northcutt and Wullimann, '88).

3. There are at least three possibilities regarding the phylogenetic origin of the dorsal preglomerular nucleus ("dorsal anterior pretectal nucleus" of Meek et al., '86a,b) in Gnathonemus. It may represent: (1) a dorsal accessory optic nucleus (sometimes considered a pretectal division, see Northcutt and Wullimann, '88), (2) a preglomerular division, or (3) the nucleus paracommissuralis of Ito et al. ('82).

The paracommissural nucleus was reported to receive a telencephalic input and to project to the cerebellum in percomorph teleosts (Ito et al., '82). However, unlike the dorsal preglomerular nucleus ("dorsal anterior pretectal nucleus" of Meek et al., ' $86 \mathrm{a}, \mathrm{b})$, nucleus paracommissuralis is located dorsal to the posterior commissure near the midline of the brain. Furthermore, there is evidence that nucleus paracommissuralis originates only with the ostariophysines (see Fig. 1) and is absent in more primitive teleosts such as osteoglossomorphs (Wullimann and Northcutt, '88).

The "dorsal anterior pretectal nucleus" of Gnathonemusalthough lacking a retinal input (Lazar et al., '84), resembles the dorsal accessory optic nucleus of other teleosts in that it projects to the corpus cerebelli (Meek et al., ' $86 \mathrm{a}, \mathrm{b})$ and receives a tectal input (this study). However, 

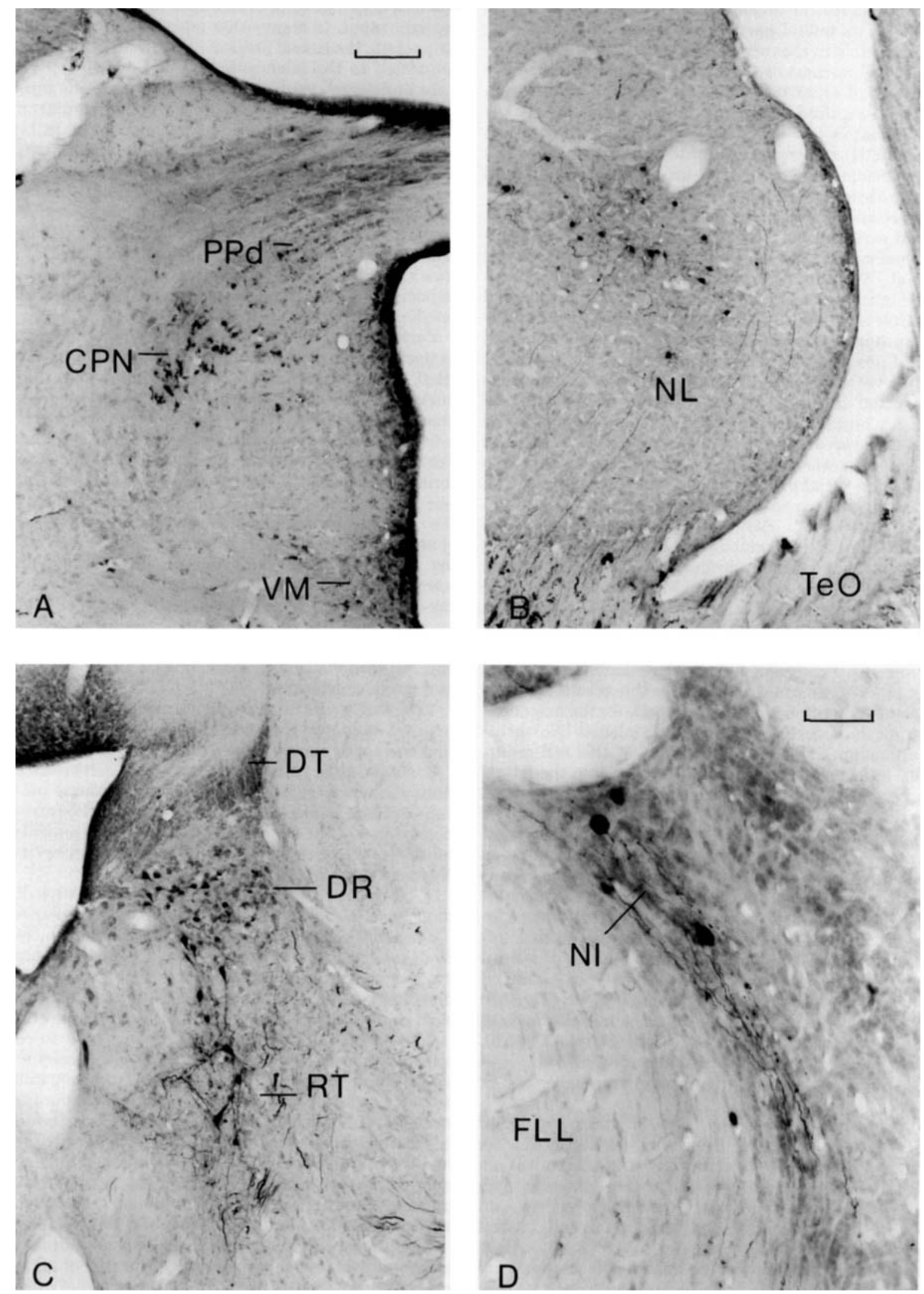


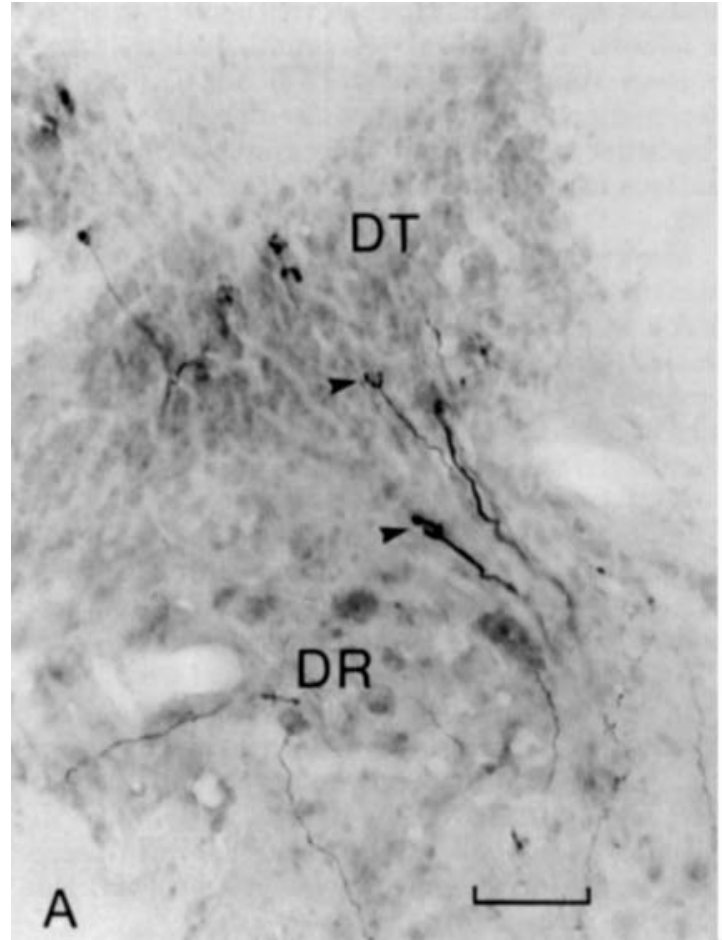

Fig. 6. Cross sections through the tegmentum and cerebellum of Gnathonemus showing details of anterograde (A) and retrograde label (B) visualized after HRP injections into the optic tectum. Medial is to the left in both frames, dorsal to the top. Bar scale $=0.05 \mathrm{~mm}$ for $\mathrm{A}$ and

neither telencephalic nor toral connections have been reported for the pretectal or accessory optic nuclei in teleosts (Northcutt and Wullimann, '88). In contrast, tectal input has also been reported for the preglomerular complex in other teleosts (Ebbesson and Vanegas, '76; Luiten, '81). Furthermore, the presence of telencephalic and toral connections, and the absence of retinal input, in the dorsal preglomerular nucleus ("dorsal anterior pretectal nucleus") in Gnathonemus, also resemble the preglomerular complex of other teleosts (see discussion on telencephalic connections). Thus if one interprets the "dorsal anterior pretectal nucleus" as a preglomerular division, only one transformation in connections must necessarily have occurred in mormyrids: a newly arisen projection to the cerebellum. In contrast, interpreting the "dorsal anterior pretectal nucleus" as the homologue of the dorsal accessory optic nucleus requires two connections (retinal input, projection to the tectum) to have been lost and two new connections (toral and telencephalic) to have arisen. Based on parsimony, we

Fig. 5. Photomicrographs of cross sections through the brain of Gnathonemus showing nuclei labeled by HRP injections into the optic tectum. Medial is to the right in A, to the left in B-D. Dorsal is to the top. Bar scale $=0.1 \mathrm{~mm}$ in A-C, $0.05 \mathrm{~mm}$ in D. A. Retrogradely labeled central and dorsal periventricular pretectal nuclei contralateral to the injection. A few labeled neurons are also seen in the contralatera ventromedial thalamus. B. Labeled cells and terminals in the lateral nucleus of the torus semicircularis. C. Two nuclei (rostrodorsal and rostral tegmental nucleus) ventral to, but not the dorsal tegmental nucleus itself, project to the optic tectum. Compare to Figure 4C. D. Labeled cells and terminal boutons within nucleus isthmi.

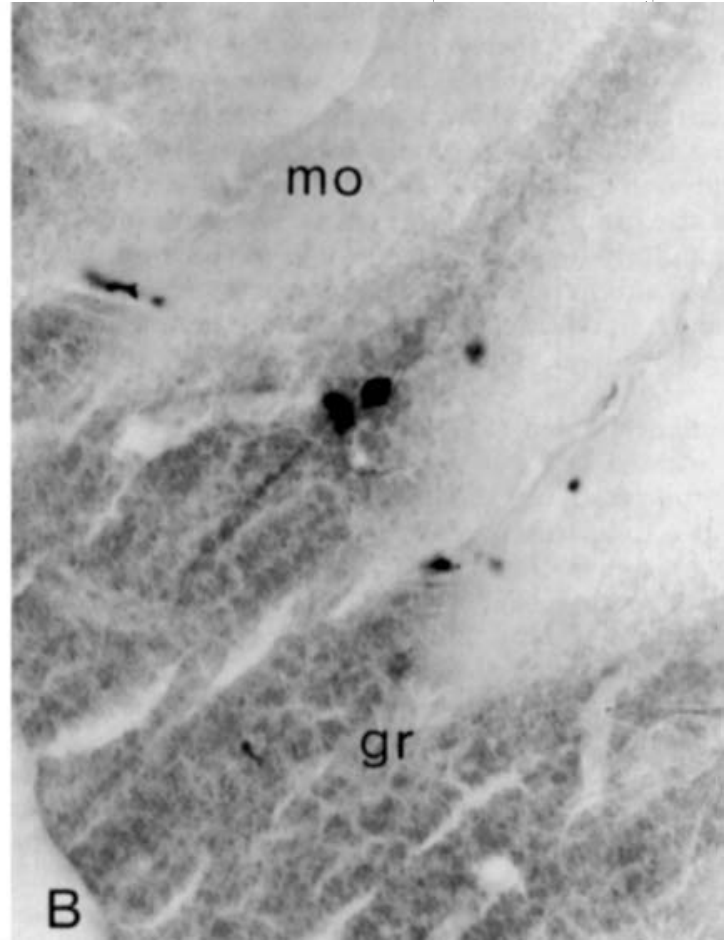

B. A. Giant axonal endings in the dorsal tegmental nucleus form a "basket" around some neurons (arrowheads). B. Cells in the valvula cerebelli (compare with Fig. 3E) that project ipsilaterally to the optic tectum.

conclude that the dorsal preglomerular nucleus (nucleus dorsalis anterior pretectalis of Meek et al., ' $86 \mathrm{a}, \mathrm{b}$ ) is a subdivision of the preglomerular area that has hypertrophied in relation to the electrosensory system in mormyrids and that it is not an accessory optic nucleus.

Consequently, the preglomerulo-cerebellar projections to the valvula (Finger et al., '81) and corpus cerebelli (Meek et al., ' $86 a, b)$ must be interpreted as uniquely derived characters (autapomorphies) for mormyrids, as preglomerulocerebellar projections have not been reported in other actinopterygians (Wullimann and Northcutt, '88, '89).

4. Interconnections between the preglomerular area and the telencephalon are unusually well developed in Gnathonemus compared to those known in other teleosts and comprise two major pathways: the octavolateralis pathway via the mediodorsal torus semicircularis to the ventral preglomerular nucleus and from there into the telencephalon; and the ampullary organ/mormyromast pathway via the lateral torus semicircularis into the dorsal preglomerular nucleus. Instead of projecting also to the telencephalon as does the ventral preglomerular nucleus, the dorsal preglomerular nucleus receives a telencephalic input and projects in turn to the corpus and valvula cerebelli.

\section{Comparison of diencephalic electrosensory circuitry between mormyrids and gymnotoids}

There is general agreement that the electrosensory modality has evolved independently in mormyrids and gymnotoids (Bullock et al., '82, '83; Bell and Szabo, '86). Thus by definition, the related central nervous circuitry is homoplasous, not homologous, as it was not present in the common 
ancestor of mormyrids and gymnotoids. The evolutionarily relevant question is, therefore, whether the structures subserving the electrosensory modality in mormyrids and gymnotoids are the result of convergence or parallelism.

Striking similarities exist in the electrosensory systems of mormyrids and gymnotoids (Bell and Szabo, '86). However, there are also fundamental differences. The torus semicircularis is laminarly organized in gymnotoids (Carr et al., ' 81 ), whereas it is subdivided into nuclei in mormyrids (Bell, '81). Furthermore, in mormyrids it is the valvula cerebelli that is most hypertrophied, not the corpus cerebelli as in gymnotoids.

In the diencephalon of gymnotoids, a nucleus electrosensorius is located in a position similar to that of the dorsal preglomerular nucleus in Gnathonemus. Both nuclei receive input from the electrosensory torus semicircularis and project to the corpus cerebelli (Carr et al., '81; Finger et al., '81; Meek et al., '86a,b; Keller et al., '89; '90). However, there are connectional differences: Whereas the dorsal preglomerular nucleus receives a massive telencephalic but a restricted tectal input (present study), neither is true of the nucleus electrosensorius (Striedter, '87; Keller et al., '90). Contrary to Keller et al. ('90), Striedter ('89a,b) found that the electrosensory toral input to nucleus electrosensorius in gymnotoids is relayed to the lateral preglomerular nucleus, which in turn projects to the telencephalon. This is clearly not the case in mormyrids. Although the ventral preglomerular nucleus projects to the telencephalon, it does not appear to be innervated by the dorsal preglomerular nucleus (Striedter, ' $89 \mathrm{~b}$ ). Thus despite some connectional similiarity, nucleus electrosensorius and the dorsal preglomerular nucleus clearly display discreet differences in circuitry. The evolutionary origin of these two nuclei, one in gymnotoids and one in mormyrids, may, therefore, also be different. Further comparative neuroanatomical and embryological work is needed to reveal whether these two diencephalic nuclei have arisen through parallel or convergent evolution.

\section{Analysis of nuclei outside the diencephalon}

We introduced the term "dorsal tegmental nucleus" for a corpopetal nucleus lying rostral to nucleus lateralis valvulae in two teleosts, Carassius and Lepomis (Wullimann and Northcutt, '88). In Carassius and other ostariophysine teleosts, the dorsal tegmental nucleus receives a projection from the telencephalon (G.F. Striedter, personal communication), a connection not seen in nucleus lateralis valvulae. In Gnathonemus, the rostral part of the corpopetal nucleus lateralis valvulae of Meek et al. ('86a,b) is apparently the same as the nucleus that receives telencephalic input in our material. Therefore, we identify this nucleus in mormyrids as the homologue of the dorsal tegmental nucleus in other teleosts.

In our tectal cases, the dorsal tegmental nucleus possesses a few peculiar, large terminal boutons (Fig. 6A). As they are similar to terminals observed in the dorsal tegmental nucleus after injections into the telencephalon, it is likely that they represent collaterals of efferent axons that reach the optic tectum from the central zone of the area dorsalis telencephali.

Ventrolateral to the dorsal tegmental nucleus lie the much larger neurons of the tectopetal (this study) and corpopetal rostrodorsal tegmental nucleus of Meek et al. ('86a,b), whose designation we have adopted. Still more ventral is the tectopetal rostral tegmental nucleus of Grover and Sharma ('81), whose term we have also adopted, as these authors were the first to show this nucleus to be tectopetal in a teleost. The rostral tegmental nucleus corresponds to nucleus ruber of Sheldon ('12) and Luiten ('81), whose designation is confusing, as the nucleus does not receive a cerebellar input (Wullimann and Northcutt, '88), and to nucleus lateralis thalami of Holmgren ('20) and Bergquist ('32).

Meek et al. ('86a,b) described a large-celled corpopetal nucleus $Q$ in the isthmic region of Gnathonemus. Later, Meek et al. ('89) identified a locus coeruleus lateral to nucleus $Q$, based on dopamine immunoreactivity. We demonstrate that these locus coeruleus neurons project bilaterally to both the optic tectum and telencephalon. A projection to the cerebellum (Wullimann and Northcutt, '88), as well as projections to the telencephalon (Northcutt, '81; Murakami et al., '83) and optic tectum (Northcutt, '82; Fiebig et al., '83), have been demonstrated for the nucleus of the locus coeruleus in various ray-finned fishes. Therefore, we prefer to include the corpopetal nucleus $Q$ of Meek et al. ('86a,b) in our larger locus coeruleus of Gnathonemus.

In this work we identified a mormyrid nucleus isthmi for the first time, on the basis of both its morphological position and reciprocal tectal connections. Only the most ventral part may correspond to nucleus isthmi of Meek et al. ('86a,b), as the bulk of the nucleus seems to correspond to part of the perilemniscal portion of the nucleus lateralis valvulae of these authors.

We recently argued that a large, histologically distinct nucleus isthmi is evolutionarily primitive (plesiomorphic) for teleosts, as it is present in all major teleost groups, including osteoglossomorphs (Wullimann and Northcutt, '88). Its unusual shape in Gnathonemus is probably due to the extraordinary development of the lateral longitudinal fascicle, which carries mechano- and electroreceptive information from the primary sensory areas of the lateral line nerves. As a result of this fascicle's hypertrophy, nucleus isthmi is pushed laterodorsally and forms an arc around the fascicle. Interestingly, nucleus isthmi is similarly shaped and displaced in the gymnotoid Apteronotus leptorhynchus (Sas and Maler, '86), apparently due to similar events during the independent evolution of the electrosensory modality in this group.

\section{ACKNOWLEDGMENTS}

We thank C.C. Bell for much appreciated advice on surgery, and D.L. Meyer and D.J. Rooney for critically reading the manuscript. D.J. Rooney also provided invaluable expert dispute during the preparation of the manuscript. For lively intellectual exchange on this and many other topics during the course of this study, we are grateful to fellow laboratory members, particularly G.F. Striedter. M.S. Northcutt assisted in many phases of the research and preparation of the manuscript. This study was supported by the Swiss National Science Foundation (M.F.W.) and NIH grants NS 24869, EY 02485 and NS 24669 (R.G.N.).

\section{LITERATURE CITED}

Adams, J.C. (1981) Heavy metal intensification of DAB-based HRP reaction product. J. Histochem. Cytochem. 29:775.

Bell, C.C. (1981a) Central distribution of octavolateral afferents and efferents in a teleost (Mormyridae). J. Comp. Neurol. 195:391-414.

Bell, C.C. (1981b) Some central connections of medullary octavolateral centers in a mormyrid fish. In R.R. Fay, A.N. Popper, W.N. Tavolga (eds): 
Hearing and Sound Communication in Fishes. New York: Springer, pp. 383-392.

Bell, C.C. (1986) Electroreception in mormyrid fish. Central physiology. In T.H. Bullock and W. Heiligenberg (eds): Electroreception. New York: John Wiley \& Sons, pp. 423-452.

Bell, C.C., and C.J. Russell (1978) Termination of electroreceptor and mechanical lateral line afferents in the mormyrid acousticolateral area. J. Comp. Neurol, 182:367-382.

Bell, C.C., and T. Szabo (1986) Electroreception in mormyrid fish. Central anatomy. In T.H. Bullock and W. Heiligenberg (eds.): Electroreception. New York: John Wiley \& Sons, pp. 375-421.

Bell, C.C., T.E. Finger, and C.J. Russell (1981) Central connections of the posterior lateral line lobe in mormyrid fish. Exp. Brain Res. 42:9-22.

Bergquist, H. (1932) Zur Morphologie des Zwischenhirns bei niederen Wirbeltieren. Acta zool. 13:57-304.

Berkelbach van der Sprenkel, $H$. (1915) The central relations of the cranial nerves in Siluris glanis and Mormyrus caschive. J. Comp. Neurol. 25:5-63.

Braford, M.R. Jr., and R.G. Northcutt (1983) Organization of the diencephalon and pretectum of the ray-finned fishes. In R.E. Davis, R.G. Northcutt (eds): Fish Neurobiology, Vol. 2. Ann Arbor: University of Michigan Press, pp. 117-163.

Bullock, T.H., D.A. Bodznick, and R.G. Northcutt (1983) The phylogenetic distribution of electroreception: Evidence for convergent evolution of a primitive vertebrate sense modality. Brain Res. Rev. 6:25-46.

Bullock, T.H., R.G. Northcutt, and D.A. Bodznick (1982) Evolution of electroreception. Trends Neurosci. 5:50-53.

Carr, C.E., L. Maler, W. Heiligenberg, and E. Sas (1981) Laminar organization of the afferent and efferent systems of the torus semicirularis of gymnotiform fish: Morphological substrates for parallel processing in the electrosensory system. J. Comp. Neurol. 203:649-670.

Ebbesson, S.O.E. (1980) A visual thalamo-telencephalic pathway in a teleost fish (Holocentrus rufus). Cell Tissue Res. 213:505-508.

Ebbesson, S.O.E., and H. Vanegas (1976) Projections of the optic tectum in two teleost species. J. Comp. Neurol. 165:161-180.

Echteler, S.M. (1984) Connections of the auditory midbrain in a teleost fish, Cyprinus carpio. J. Comp. Neurol. 230:536-551.

Echteler, S.M., and W.M. Saidel (1981) Forebrain connections in the goldfish support telencephalic homologies with land vertebrates. Science 212:683685.

Erdl, Dr. (1846) Üeber das Gehirn der Fischgattung Mormyrus. Gel. Anz. Königl. Bayer. Akad. Wissensch. 23:403-407.

Fiebig, E., S.O.E. Ebbesson, and D.L. Meyer (1983) Afferent connections of the optic tectum in the piranha (Serrasalmus nattereri). Cell Tissue Res. 231:55-72.

Finger, T.E., C.C. Bell, and C.J. Russell (1981) Electrosensory pathways to the valvula cerebelli in mormyrid fish. Exp. Brain Res. 42:23-33.

Franz, V. (1912) Das Moryridenhirn. Zool. Jb. 32:465-492.

Franz, V. (1913) Faseranatomie des Mormyridengehirns. Anat. Anz. 45:271279.

Franz, V. (1921) Zur mikroskopischen Anatomie der Mormyriden. Zool. Jb. 42:91-148.

Grover, B.G., and S.C. Sharma (1981) Organization of extrinsic tectal connections in goldfish (Carassius auratus). J. Comp. Neurol. 196:471488.

Hanker, J.S., P.E. Yates, C.B. Metz, and A. Rustioni (1977) A new specific, sensitive and non-carcinogenic reagent for the demonstration of horseradish-peroxidase. Histochem. J. 9:789-792.

Harder, W. (1968) Die Beziehungen zwischen Elektrorezeptoren, elektrischem Organ, Seitenlinienorganen und Nervensystem bei den Mormyridae. Z. Vergl. Phys. 59:272-318.

Haugede-Carre, F. (1979) The mesencephalic exterolateral posterior nucleus of the mormyrid fish Bryenomyrus niger: Efferent connections studied by the HRP method. Brain Res. 178:179-184.

Haugede-Carre, F. (1983) The mormyrid mesencephalon. II. The mediodorsal nucleus of the torus semicircularis: Afferent and efferent connections studied with the HRP method. Brain Res. 268:1-14.

Holmgren, N. (1920) Zur Anatomie und Histologie des Vorder-und Zwischenhirns der Knochenfische. Acta Zool. 1:137-315.

Hopkins, C.D. (1986) Behavior of Mormyridae. In T.H. Bullock and W. Heiligenberg (eds): Electroreception. New York: John Wiley \& Sons, pp. $527-576$.

Hopkins, C.D. (1988) Neuroethology of electric communication. Ann. Rev. Neurosci. 11:497-535.
Ito, H., and R. Kishida (1978) Telencephalic afferent neurons identified by the retrograde HRP method in the carp diencephalon. Brain Res. 149:211-215.

Ito, H., and H. Vanegas (1984) Visual receptive thalamopetal neurons in the optic tectum of teleasts (Holocentridae). Brain Res. 290:201-210.

Ito, H., T. Murakami, and Y. Morita (1982) An indirect telencephalocerebellar pathway and its relay nucleus in teleosts. Brain Res. 249:1-13.

Ito, H., Y. Morita, N. Sakamoto, and S. Ueda (1980) Possibility of telenceph alic visual projection in teleosts, Holocentridae. Brain Res. 197:219-222.

Keller, C.H., M. Kawasaki, and W. Heiligenberg (1989) The anatomical and functional organization of a sensory-motor interface, the nucleus electrosensorius of Eigenmannia. In J. Erber, R. Menzel, H.-J. Pfluger and D. Todt (eds): Neural Mechanisms of Behavior. Proc. 2nd Int. Congr. Neuroethology. Stuttgart: G. Thieme, p. 99.

Keller, C.H., L. Maler, and W. Heiligenberg (1990) Structural and functional organization of a diencephalic sensory-motor interface in the gymnotiform fish, Eigenmannia. J. Comp. Neurol. 293:347-376.

Lauder, G.V., and K.F. Liem (1983) The evolution and interrelationships of the actinopterygian fishes. Bull. Mus. Comp. Zool. 150:95-197.

Lazar, G., S. Libouban, and T. Szabo (1984) The mormyrid mesencephalon. III. Retinal projections in a weakly electric fish, Gnathonemus petersii. J. Comp. Neurol. 230:1-12.

Luiten, P.G.M. (1981) Afferent and efferent connections of the optic tectum in the carp (Cyprinus carpio L.). Brain Res. 220:51-65.

McCormick, C.A. (1989) Central lateral line mechanosensory pathways in bony fish. In S. Coombs, P. Görner, and H. Münz (eds): The Mechanosensory Lateral Line: Neurobiology and Evolution, Berlin: Springer, pp. 341-364.

Maler, L., H.J. Karten, and M.V.L. Bennett (1973a) The central connections of the posterior lateral line nerve of Gnathonemus petersii. J. Comp. Neurol. 151:57-66.

Maler, L., H.J. Karten, and M.V.L. Bennett (1973b) The central connections of the anterior lateral line nerve of Gnathonemus petersii. J. Comp. Neurol. 151:67-84

Meek, J., H.W.J. Joosten, and H.W.M. Steinbusch (1989) Distribution of dopamine immunoreactivity in the brain of the mormyrid teleost Gnathonemus petersii. J. Comp. Neurol. 281:362-383.

Meek, J., R. Nieuwenhuys, and D. Elsevier (1986a) Afferent and efferent connections of cerebellar lobe $\mathrm{C} 1$ of the mormyrid fish Gnathonemus petersii: An HRP study. J. Comp. Neurol. 245:319-341.

Meek, J., R. Nieuwenhuys, and D. Elsevier (1986b) Afferent and efferent connections of cerebellar lobe $\mathrm{C} 3$ of the mormyrid fish Gnathonemus petersii: An HRP study. J. Comp. Neurol. 245:342-358.

Murakami, T., H. Ito, and Y. Morita (1986a) Telencephalic afferent nuclei in the carp diencephalon, with special reference to fiber connections of the nucleus preglomerulosus pars lateralis. Brain Res. 382:97-103.

Murakami, T., T. Fukuoka and H. Ito $(1986 \mathrm{~b})$ Telencephalic ascending acousticolateral system in a teleost (Sebastiscus marmoratus), with special reference to the fiber connections of the nucleus preglomerulosus. J. Comp. Neurol. 247:383-397.

Murakami, T., Y. Morita, and H. Ito (1983) Extrinsic and intrinsic fiber connections of the telencephalon in a teleost, Sebastiscus marmoratus. J. Comp. Neurol. 216:115-131.

Nieuwenhuys, R. (1963) The comparative anatomy of the actinopterygian forebrain. J. Hirnforsch. 6:171-192.

Nieuwenhuys, R., and C. Nicholson (1969a) A survey of the general morphology, the fiber connections, and the possible functional significance of the gigantocerebellum of mormyrid fishes. In R. Llinas (ed): Neurobiology of cerebellar evolution and development. Chicago: AMA, pp. 107-134.

Nieuwenhuys, R., and C. Nicholson (1969b) Aspects of the histology of the cerebellum of mormyrid fishes. In R. Llinas (ed): Neurobiology of cerebellar evolution and development. Chicago: AMA, pp. 135-169.

Nieuwenhuys, R., E. Pouwels, and E. Smulders-Kersten (1974) The neuronal organization of cerebellar lobe $\mathrm{C} 1$ in the mormyrid fish Gnathonemus petersii (Teleostei). Z. Anat. Entwickl.-Gesch. 144:315-336.

Northcutt, R.G. (1981) Localization of neurons afferent to the telencephalon in a primitive bony fish, Polypterus palmas. Neurosc. Letters 22:219-222.

Northcutt, R.G. (1982) Localization of neurons afferent to the optic tectum in longnose gars. J. Comp. Neurol. 204:325-335.

Northcutt, R.G., and A.B. Butler (1980) Projections of the optic tectum in the longnose gar, Lepisosteus osseus. Brain Res. 190:333-346.

Northcutt, R.G., and M.F. Wullimann (1988) The visual system in teleost fishes: Morphological patterns and trends: In J. Atema, R.R. Fay, A.N. Popper and W.N. Tavolga (eds): Sensory biology of aquatic animals. New York: Springer, pp. 515-552. 
Sas, E., and L. Maler (1986) Identification of a nucleus isthmi in the weakly electric fish Apteronotus leptorhynchus (Gymnotiformes). Brain Behav. Evol. 28:170-185.

Sheldon, R.E. (1912) The olfactory tracts and centers in teleosts. J. Comp. Neurol. 22:177-339.

Stendell, W. (1914a) Die Faseranatomie des Mormyridengehirns. Abh. Senckenb. Naturf. Ges. 36:1-39.

Stendell, W. (1914b) Einige Bemerkungen zum Aufsatz von V. Franz: "Faseranatomie des Mormyridengehirns." Anat. Anz. 46:30-32.

Stendell, W. (1914c) Morphologische Studien an Mormyriden. Verh. dtsch. zool Ges. 24:254-261.

Striedter, G.F. (1987) Does nucleus electrosensorius of gymnotoids have a homologue in the diencephalon of non-electroreceptive teleosts? Soc Neurosci. Abstr. 13:130.

Striedter, G.F. (1989a) Similar electrosensory pathways to the telencephalon in siluroid and gymnotoid electreceptive teleosts. In J. Erber, R. Menzel, H.-J. Pflüger and D. Todt (eds): Neural Mechanisms of Behavior. Proc. 2nd Int. Congr. Neuroethology. Stuttgart: G. Thieme, p. 104.

Striedter, G.F. (1989b) Different electrosensory pathways to the telenceph- alon in siluriform teleosts, mormyrid teleosts and cartilaginous fishes. Soc. Neurosci. Abstr. 15:32.

Suzuki, N. (1932) A contribution to the study of the mormyrid cerebellum. Annotes zool. Jap. 13:503-524.

Szabo, T. (1983) Cerebellar pathways in the brain of the mormyrid teleost fish. Acta Morphol. Acad. Sci. Hung. 31:219-234.

Weston, J.K. (1937) Notes on the telencephalon of Mormyrus and Gnathone. mus. Kon. Akad. v. Wetensch. Amsterdam, Proc. sect. sc. 40:894-904.

Wullimann, M.F., and R.G. Northcutt (1987) Telencephalic and retinal projections allow reinterpretation of the diencephalon in mormyrids. Soc. Neurosci. Abstr. 13:130.

Wullimann, M.F., and R.G. Northcutt (1988) Connections of the corpus cerebelli in the green sunfish and the common goldfish: A comparison of perciform and cypriniform teleosts. Brain Behav. Evol. 32:293-316.

Wullimann, M.F., and R.G. Northcutt (1989) Afferent connections of the valvula cerebelli in two teleosts, the common goldfish and the green sunfish. J. Comp. Neurol. 289:554-567.

Wullimann, M., and D.G. Senn (1981) Zur Morphologie der LateralisInnervation bei Mormyriden-Fischen (Brienomyrus spec. Taverne 1971 Mormyridae, Teleostei). Verhandl. Naturf. Ges. Basel 92:63-72. 